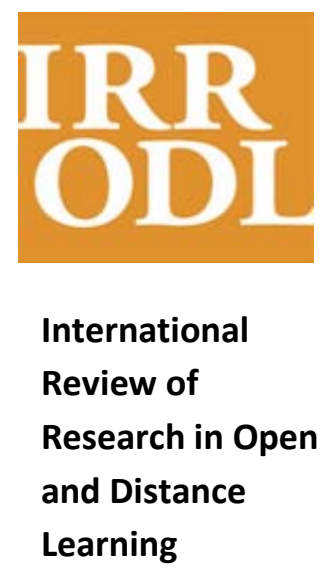

Vol. 12.4

May - 2011

\section{Re-Thinking Sustainable Education Systems in Iceland: The Net-University Project}

\author{
Frank Rennie \\ Lews Castle College UHI, UK \\ Sigurbjörg Jóhannesdóttir \\ Icelandic Ministry of Education, Science and Culture, Iceland \\ Stefania Kristinsdottir \\ The East Iceland Knowledge Network, Iceland
}

\begin{abstract}
The recent economic crisis in Iceland has raised issues of the sustainability of Icelandic higher education to new levels of importance. A key strategy in relation to this economic crisis is to consider the merger of the four public universities in Iceland and to introduce a much higher enegagement with online and open delivery methods of higher education.The Net-University Project was an EU Leonardo-funded initiative to compare approaches to open and distance education in Iceland, Sweden, and Scotland, with additional lessons from Atlantic Canada. In particular, it sought to focus on the transfer of innovation in continuing university education, with particular emphasis on the development and delivery of online higher education courses throughout rural Iceland (i.e., outside of Reykjavik). The partners concentrated on how knowledge and experience about distributed and distance learning models could be transferred between the partner countries and how such models can be integrated into the education system to better support higher education and lifelong learning. There was a particular interest in the practical use of open educational resources (OER) for course design and in the sharing of these course modules among university partners. Some good practice and lessons from OER use in course creation are listed.
\end{abstract}

Keywords: Distance education; open educational resources; knowledge transfer

\title{
Introduction: The Icelandic Context
}

Iceland has a total area of 103,000 square kilometres with a population of approximately 320,000. Nearly half of the national population is located in the dense capital area. Altogether, there are 78 municipalities in Iceland (Statistics Iceland, 2009). The educational system in Iceland is administered by the Ministry of Education, Science and Culture. The fundamental principle of the system is that everyone should have equal opportunities to acquire an education, irrespective of 
economic status, residential location, gender, religion, handicap, and cultural or social background (Ministry of Education, Science and Culture in Iceland, 2005).

Education in Iceland is traditionally within the public sector. There are very few private schools in Iceland and almost all of them receive public funding. The Icelandic educational system is divided into four levels: pre-school, compulsory school, upper-secondary school, and higher education. There are 7 universities, 32 upper-secondary schools, 10 knowledge centres, 31 learning centres, as well as 7 research centres from the University of Iceland (UI) and 2 university centres in the Western-Fjords and in South Iceland that focus on developing and supporting university education (Figure 1).

In addition to the research and learning centres shown in Figure 1, about 100 knowledge centres operate around the country, including regional nature-institutions, development centres, and cultural institutions, some of them involved in university education. In 2009, the Ministry of Education and Culture appointed a group with the role of mapping and investigating the potential for collaboration between research and development services and cultural centres or institutions in Iceland.

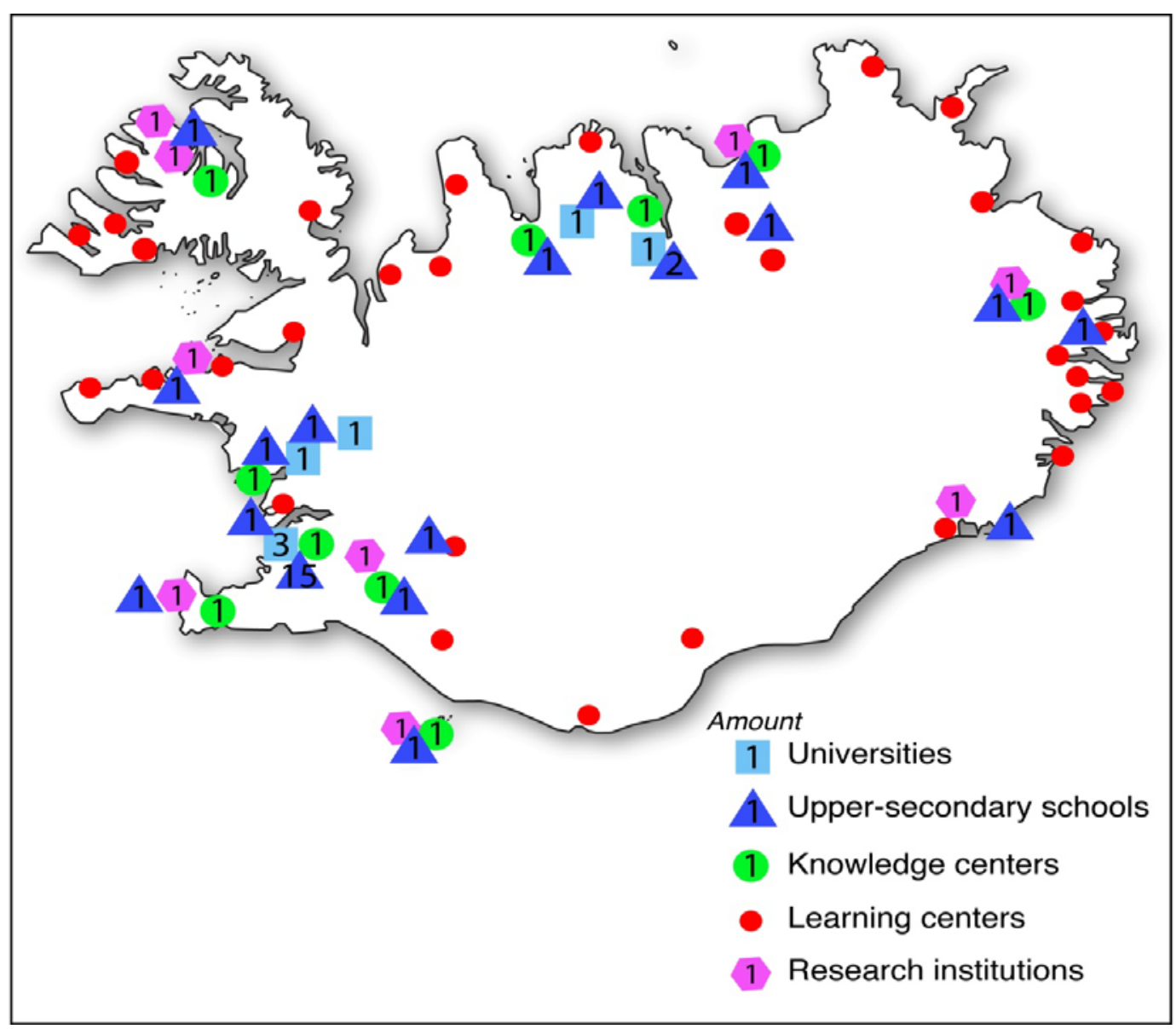

Figure 1. Knowledge centres, learning centres, universities, and upper-secondary schools in Iceland, 2010. 
Most study programmes offered at the university level are only available in the capital area as face-to-face study, but some distance provision is delivered (Table 1. Note: some students in blended study are counted by more than one mode). Only a few study programmes are available in distance or distributed mode, and there is almost no cooperation between universities about what programmes are offered by such methods. At the upper-secondary level, eight hosts offer some programmes in distance teaching, while other programmes are only offered in face-to-face teaching. Iceland is committed to the fundamental principle that everyone should have equal opportunities to acquire an education, regardless of their location, and this has prompted a realisation of the need to collaborate more efficiently between the universities, as well as between higher education institutions and schools or local learning centres.

Table 1

Total Students at University Level in Iceland

\begin{tabular}{|l|rrrrr|}
\hline Universities & $\mathbf{2 0 0 2}$ & $\mathbf{2 0 0 4}$ & $\mathbf{2 0 0 6}$ & $\mathbf{2 0 0 8}$ & $\mathbf{2 0 0 9}$ \\
\hline Total students & 13,900 & 16,096 & 16,738 & 18,104 & 18,226 \\
Day courses & 11,807 & 13,089 & 14,536 & 14,514 & 14,592 \\
Evening courses & 456 & 437 & 196 & 157 & 369 \\
Distance learning & 1,936 & 2,751 & 2,439 & 3,340 & 4,047 \\
\hline
\end{tabular}

Distance education was established to make education accessible and thereby create opportunities for studies that are independent of where people live and what their financial status or personal circumstances are (e.g., a disability). Distance education in Iceland has also grown over the last decade, with a strong indication of continuing growth (Figure 2). In the past decades, an emphasis has been placed on developing the technical aspects of distance education, but now an increased emphasis on pedagogical research may lead to improved education. Finally, there is an emphasis on making distance education more economical by further developing the number of students involved in distance education and by extending the range of courses. 


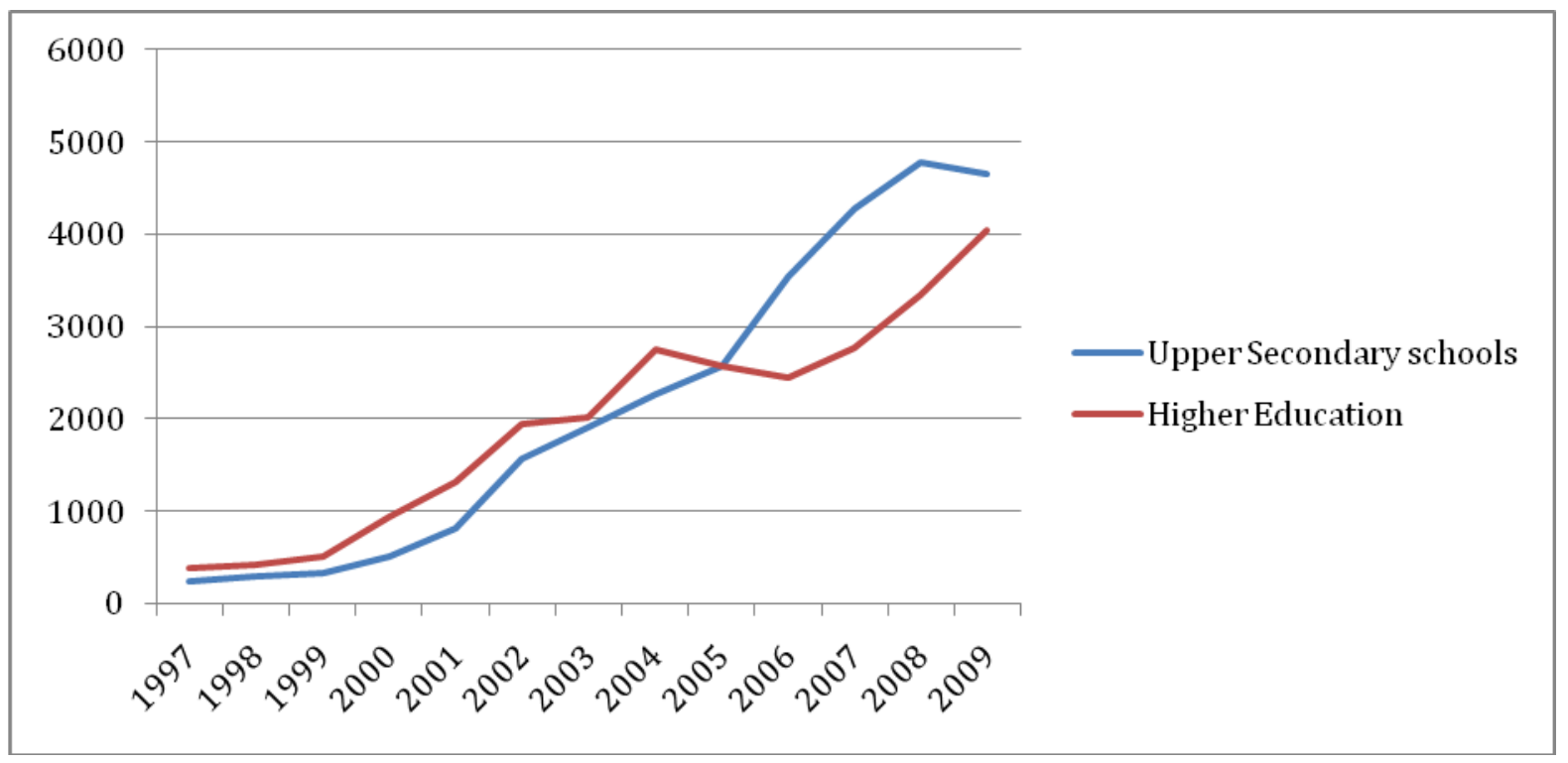

Figure 2. Total number of students participating in distributed learning (Source: Statistics Iceland, 2009).

Distance and distributed education is regulated in the same manner as traditional education; however, no conscious policy for common platform(s) for distributed education is followed and overall no formal collaboration network for distance or distributed education exists. The responsibility for the execution of distance teaching is carried out by several parties within Iceland's upper-secondary schools and universities. The maturity and form of distance education depends on which school is involved and even what type of distance studies are being offered. The development of distance education is practiced separately within each school and university (and can even be very different between departments).

The suggestion from this project, together with the conclusions of the previous study (Thórsteinsdóttir et al., 2007), is that distance education at upper-secondary and university levels in Iceland would benefit hugely from joint collaboration between schools and universities, for example, through sharing facilities, infrastructure, and staff. Lifelong learning and educational centres are working with the universities in Iceland, but it has been suggested that a more formal setting should be formed for broad-scope discussions on distributed education. University representatives are also looking towards more cooperation with overseas countries. It is clear that a policy for distance and distributed education is needed within each of the universities and upper-secondary schools in Iceland, as well as a more holistic policy for the country's overall education system.

Kvasir, the association of education and lifelong learning centres in Iceland, works with the universities and upper-secondary schools. Its main goal is to increase the availability of lifelong learning and distance learning at these levels. Educational levels in Iceland are generally lower in the rural areas than in the densely populated capital area, and this undermines the importance of demonstrating equal opportunities for education on a national basis. 


\section{The Net-University Project}

The Net-University Project was funded to compare approaches to open and distance education in Iceland, Sweden, and Scotland, with additional lessons from Atlantic Canada. The project ran from 2008-2010, co-ordinated by the East Iceland Knowledge Network, with academic partners from Lews Castle College (UHI Millennium Institute, Scotland) and Jönköping University (Sweden). Also involved in the project as contractors were the University of Akureyri (Iceland) and Smart Labrador (for the province of Newfoundland and Labrador in Canada).

There were five clear objectives of the Net-University project:

1. to open universities to the public as an essential part of continued vocational training and lifelong learning;

2. to make university education more accessible to adults and inhabitants of rural areas, including students undertaking self-directed learning;

3. to create a platform for cooperation, between universities and continuing education centres in Iceland and abroad, in developing new courses and degrees;

4. to create a platform for continuing education centres and institutions in rural areas to develop university-level courses related to vocational educational needs;

5. to develop methodologies and support for students in distance education.

Although the idea of an Icelandic university network has been developing for several years, a similar concept for secondary education has not emerged to the same extent. In 2005, the Ministry of Education established a policy group on distance university education that produced two reports: one on distance education in Iceland (Thórsteinsdóttir, 2006) and another on the organisation of online or distance university education in Sweden, Scotland, Canada, and France (Thórsteinsdóttir et. al, 2007). Following up this work, Kvasir, the association of education centres around the country, nominated The East Iceland Knowledge Network (TEIKN) to work further on the development of the Icelandic Netháskóli or Distance University. Based on this nomination, a preparatory group for the Distance University was formed in 2007 within the Ministry of Education, in cooperation with TEIKN. The Ministry supported the group to deliver two outputs:

1. A demonstration model and framework for a Distance University of Iceland, presenting the necessary information, a site map, and ways in which the model could be further developed. At this point the group was only focusing on a Web site listing content related to distance education in Iceland (Jóhannesdóttir, 2007).

2. A report, including a needs analysis and system definition, on how content related to distance education could be transferred from universities’ IT systems and categorised into a centralised database. Issues such as possible services to distance students were also addressed, for example how can learning centres work better with universities in servicing their students' needs and in sharing access to students' calendars, information on exams, and contact information to be able to inform students of local facilities and services? (Jóhannesdóttir, 2008). 
The first report was presented at a conference in the autumn of 2007, where representatives from the universities, the Ministry, and the education centres met to discuss ways to further develop the Distance University concept. Prior to the conference, representatives from TEIKN and the Ministry visited all the universities in Iceland to introduce the idea of the Distance University and discuss their possible involvement in the project.

The second report was a follow-up on the conference and the meetings with the universities. It was developed in cooperation with university representatives (different ones than in the first round) from IT and distance education departments. The report was handed to the Ministry in January 2009, with suggestions on next steps, a draft of a project, and a financial plan for implementation. During the project, the idea for a Distance University was changed from a plan to simply include information on courses and services for distance students to the concept of a holistic and categorized database on university education in Iceland. This database would include categorised information on distance education, courses in English, and short courses as part of lifelong learning, and so forth.

The construction of this holistic database supports the ongoing work of the Ministry to reconstruct the Icelandic university education system and to save money without decreasing services. A similar situation applies to the upper-secondary level, and therefore it would seem sensible to coordinate these networks into one system of lifelong learning, covering both uppersecondary and higher education in Iceland. From this position, the Net-University project serves to provide potential guidelines for the Ministry of Education and Culture's policy development and for collaborative work among the universities and upper-secondary schools in Iceland.

\section{Conceptual Framework}

In the Icelandic context, where a number of universities, research institutions, and higher education learning centres are scattered around the country but the vast majority of students are located in the capital city, there is a strong desire to develop networked solutions for educational delivery. From a broad range of options (Thórsteinsdóttir et al., 2007; Mason \& Rennie, 2008), early investigation by Icelandic institutions identified open and flexible delivery through the existing network of regional centres to have strong similarities with the developing model in Scotland (Hills \& Lingard, 2003; Rennie, 2008).

An earlier study of networked learning gave broad definitions of the terminology and pedagogy and listed among its advantages that network learning "is appropriate for learning situations where the participants cannot gather in a classroom because they are dispersed geographically or have tight schedules, but would benefit from learning together" (Haughey \& Anderson, 1998, p. 8). The current project considered better networking of educational provision within Iceland (particularly using ICT solutions) as a means to share resources, avoid inefficient overlap, and improve quality learning experiences for students. This thinking led to 1) detailed discussions of opportunities for networking within Iceland; 2) consideration of opportunities for international networking; and 3) the improved use of open educational resources (OER) as a basis for 
curriculum development. The latter point was specifically influenced by the frameworks for OER development and use proposed by Gurell and Wiley (2010) and the Commonwealth of Learning (2005). A subsidiary consideration was the assumption that the costs of collaborative sharing of open-access educational materials by a network of Icelandic institutions would be more favourably received by government in the midst of the current financial crisis. The realisation of the need for a substantial step change from the current educational situation, in the face of acute financial cutbacks, has prompted a greater awareness of the possibility of sharing courses between existing universities by utilising online education.This is new thinking in the Icelandic educational system and it would mean re-thinking the funding system that is currently built on face-to-face teaching. Advantages are not just in cost savings and labour efficiency but also in investing in (decentralised) rural areas and driving up quality by networking the best resources. Challenging these idealised opportunities are the elements of the "real" system, as summarized by Davis (2004, p. 98), in which he notes that

any or all of the following deviations from the ideal occur: limited resources, legacy systems that have loyal advocates, key staff who must be retrained, unworkable policies and practices that you never knew existed, inadequate governance processes, [and] administrative systems that might or might not be made to work with the new systems.

All of these components can be recognized as being relevant to the current Icelandic context.

\section{Knowledge Transfer}

Several models of good practice were identified and documented in a report to the Ministry of Education in Iceland (Thórsteinsdóttir et al., 2009). In Scotland, the UHI Millennium Institute (UHI) is a network of 13 academic partners - colleges, research institutions, and 50 plus local learning centres - located throughout the Highlands and Islands of Scotland. Depending on the course, students may be taught face-to-face at one academic site or have access to a distributed course that is taught by staff from multiple campus sites. The latter may be delivered fully online or through a blended approach (e.g., including face-to-face or some video conference tuition.) The UHI has an internal formula to reward the different elements of student engagement, with elements of institutional funding being allocated for tuition, for "hosting" the student (i.e., the provision of classrooms, computer room, libraries, etc.), and for student enrolment (i.e., recruiting the student to the UHI and processing associated paperwork). Each element may be carried out by a different partner in the network.

In Newfoundland and Labrador, we noted that the entire school-college-university system uses a common online platform to link with learners and this has distinct advantages in terms of lifelong learning provision and community education.

In Sweden, local learning centres are owned by the municipality, not the university, and are regarded in much the same light as public libraries and public recreation centres. 
The partner institutions in Scotland, Canada, and Sweden all have a specific locus in the engagement of higher education provision in the sustainable development of their own geographical regions.

A natural development during this project was to investigate a methodology that would utilise open educational resources in the construction of higher education courses that could be adapted to the different educational contexts and cultural nuances of the different institutional partners. A pilot module on environmental issues was developed, using OER to test this methodology in practice, and following positive feedback from the partners, this will be the basis of future collaboration.

\section{The Adoption of OER in Course Design}

At an early stage in the Net-University project, it became apparent that for the academic partners to gain the maximum benefit from a more flexible approach to educational provision, the digital resources and supporting software should be free or extremely inexpensive. This led naturally to a consideration of only open access materials, freeware, open source software, open access journals, and other open educational resources (OER). The study was informed by a recent OECD report in which it was recognised that although the standard definition of OER is "digitised materials offered freely and openly for educators, students and self-learners to use and reuse for teaching, learning and research” (OECD, 2007, p.10), in practice this covers a very wide area. This very broad definition of OER was adopted to include any digital materials that are able to be easily accessed, shareable, and freely available for reuse within the very broad constraints of Creative Commons licensing for use in the construction of educational "lessons."

In the academic literature, there is an ongoing debate between "big OER" (institutionally supported, top-down) and "small OER" (created by individual users on the fly, bottom-up) (Weller, 2010a). Downes (2006), among others, distinguishes between OER systems by funding models, technical models, and content models and attributes very different functions and requirements to these different structures. In the case of this study, we limited ourselves to the coproduction model, that is, the consideration of OER reuse that was essentially the repurposing of open access educational resources that were co-produced, decentralised, and low-cost in the belief that these would be more sustainable in the current Icelandic situation (Wiley, 2007; Guthrie, Griffiths, \& Maron, 2008). It soon became apparent that while there are many thousands of open educational resources available via the Internet (e.g., SideCAP, 2010; Rennie \& Weller, 2010), there are significantly fewer good examples of the systematic reuse of OER to construct open access courses at the higher education level. It was therefore decided that the best way to illustrate the process and the value of OER in course design was to create actual exemplars and document the process. Preference was given to non-institutional, open-access software for the creation or manipulation of educational resources, for example, Jing for screencasts, Picasa and Flickr for images, Wetpaint or PBwiki for hosting wikis, and Moodle for the online learning platform. 


\section{Process}

In order to demonstrate the generic value of the idea, it was decided to create a general course on a subject area with a very broad appeal. Accordingly (and purely as a vehicle to experiment with the pedagogic process), due to the Icelandic interest in generating a course relating to National Park management, the topic People and Nature was selected on the grounds that this specific subject area is an important issue in environmental and societal sustainability and affects all people directly or indirectly.

1. The first step was to identify the main headings for the structure of the course content. These should be the key topics for discussion with students and the most important points around which tutors would like to see learning occur.

2. Using Internet browsers, the next stage was to search and identify relevant digital resources that matched the main headings of our course structure. Priority was given to the identification of open educational resources, as defined above, that could be used and recombined with other resources to produce systematic educational activities of a high quality. Initially, no real distinction was made whether these resources were digital photographs, diagrams, maps, video or audio clips, journal articles, or other materials.

3. The resources were then grouped according to their match with the main headlines of the course structure, and a storyboard was created to link the most relevant OER in a sequential manner to construct a lesson plan or educational activity.

4. The course team then created some wrap-around text to link these OER and to place them in an appropriate educational context with respect to the level and learning objectives of the course. This enabled the team to structure the course materials in a manner that was pedagogically sound and which they considered to be educationally relevant and interesting.

5. It was at this stage that the course team stood back to review the entire scope and contents of the course and its educational resources. As was to be expected, several gaps were identified in the range of these resources. After another brief but unsuccessful attempt to locate relevant OER to fill these gaps, it was decided to create our own OER which we could add to the course and then to contribute these new OER to the global pool of open educational resources with a Creative Commons licence. As a result, web photograph albums (with explanatory captions), screencasts, and a video clip were added. Consideration is being given to web streaming of two or more lecture presentations to be recorded on relevant topics.

6. We now had to make a decision about the media that we wanted to use to deliver the course and the OER that we had selected. In this case, because the exercise was undertaken as a pilot example to demonstrate the process, we decided to host the course in four media formats: 
a. on a publicly accessible wiki (open to Internet view; write-restricted to trusted editors) ${ }^{1}$;

b. as a simple MS Word document for printing and distribution in situations of restricted Internet access;

c. as a simple Open Office document (free and open) for people in the same situation but without access to MS Word;

d. as a single document on a CD (for those without any online access).

7. The next stage was to license the course using the Creative Commons protocols, make the pilot course available for students, and invite review and or further refinements of the course contents and resources. This process is summarised in Figure 3.

In general, we sought open access resources that would have a relevance to northern Europe and that were in English (this being the common project language, as well as the fact that both Iceland and Sweden occasionally teach higher education courses in English). The selection of material was made for an introductory level course, although in reality multiple levels would need to be considered. The project also discussed the idea of providing podcasts in other languages (e.g., Swedish, Icelandic, and Gaelic) to give a wider cultural setting to the resources, but in the end this was not completed due to lack of time.

\section{Difficulties/Challenges}

There have been three main challenges to this operational process. Firstly, it was very timeconsuming in the initial stage to search and identify suitable OER (this was particularly true for relevant academic papers published in open access journals). Although there are many tens of thousands of OER available, they are not necessarily tagged in an appropriate manner to suit the context of each personal search, so a lot of time was spent at the start simply searching and browsing a diverse array of OER sources, using different but related search terms. Considerable Internet skills and some lateral thinking were useful in hunting down appropriate OER, but as with other procedural tasks, these abilities are likely to improve with constant practice.

Secondly, when the assemblage of open educational resources was collected, it was apparent that there is a diversity of quality between the individual OER. The resources also vary in length and in the academic level of complexity, but together this facilitates the inclusion of the OER in different functional roles within the completed course, that is as exemplars of introductory concepts, learning activities, and/or components of further reading.

Thirdly, there were inevitably some gap areas where appropriate OER were not identified or were not considered to be of sufficient quality to be reused (e.g., perhaps too specific or too generic in its context.) In these cases, the challenge was to generate new and relevant OER from personal resources or from those of the institution and then to license and include these in the global OER

\footnotetext{
${ }^{1}$ http://netuniversity.wetpaint.com/page/People+and+Nature+course
} 
pool. While initially a matter of minor apprehensiveness, after some assistance and some practice, a range of very good still images, audio clips, screencasts, and other digital OER were successfully created for addition to the course pool. These were added to Picasa, Flickr, and so forth and then linked to the structure of the course on the course wiki. It goes without saying that starting completely from scratch to produce new OER can at first be rather daunting, but as more are created by the course team and by the institution, and as experience is gained, a large pool of contextually appropriate OER can be generated for teaching and learning support.

From the student perspective, three key challenges were identified by our user group. Firstly, the need to download and install external (independent of the institution) software (e.g., iTunes) may be difficult for users with basic computer literacy. There may also be an issue with obtaining download permissions when students are using a computer terminal at work or in a public learning centre or library. Secondly (and related), it may occasionally be required for users to register with service providers in order to access relevant software, and though the process itself may be relatively simple, there may be an ethical barrier on the part of some users to share their private profile data with corporate providers. When educational resources remain hosted on the university online platform, the contract of confidentiality is solely between the student and the institution; this is extended into multi-party agreements with potentially less control of security when the user makes agreements with providers not subject to control by the university. Thirdly and more generally, the issues of credibility and the status of digital scholarship are in transition, heavily influenced by three new characteristics of academic practice: the fact that educational resources are becoming more digital, networked, and open (Weller, 2010b). For end users, there is a growing requirement to be able to identify "good" (i.e., high-quality) and "bad" (i.e., inaccurate, biased, or low quality) Internet-based resources, and although this issue concerns more than just OER, the openness of OER has tended to encourage students to forage on the Internet in areas without the ability of the lecturer to pre-select relevant resources at a suitable level. Learners frequently feel that they need to be specifically trained to locate and recognize good materials on the Internet.

In the pilot online course, the choice of a free wiki provider (Wetpaint) meant that commercial advertisements were included in marginal frames of the wiki, and this non-educational clutter may have proved to be confusing or annoying to student users. In fact, this software provider offers a facility to have advertising removed from their wikis which have an educational purpose, but the project did not seek to make use of the facility due to the short timeframe and temporary nature of the pilot. A more serious concern relates to the ethical and long-term planning issues of hosting the educational materials of an institution through an external service provider. In the case of this project, the ethical issues are considered to be minimal as students were not being asked to give their information to a third party in order to view the course (only university-based editors were granted write-permissions; read-access is available to all). Secondly, the issues of backup and ensuring access to the information on the external site were not regarded as a problem, again due to the temporary nature of the wiki. In the longer timeframe, there is a wider discussion to be had about balancing the advantages of an internal wiki (university-hosted) that ensures data security, backup services, and so forth versus the greater diversity, versatility, and speed of change provided by external (commercial) software suppliers. This is part of a wider 
discussion that balances the closed-but-secure services provided by universities' ICT against the more popular but open facilities through, for example, WordPress, Facebook, and YouTube.

\section{Perceived Advantages}

A major advantage is the speed with which it is possible to construct high quality courses, using digital OER that have been created by other trusted sources. An estimation of the time taken to construct a course in this way will vary enormously, but it has taken as little as 3-4 weeks rather than many months of the conventional design structure, where each piece of text and teaching resource is generated anew from scratch. Another advantage, then, is the ease of collaboration with others in the generation of new educational perspectives without having to reinvent the wheel. This encourages a good teamwork approach. In addition, the OER method of course construction has the effect of lowering the costs of course production while at the same time generating publicity and inter-institutional collaboration. From a wider perspective, it is a strong, positive feature that the creation and reuse of OER adds value to the global community of learners and scholars, not simply in our own institutions or those of our co-workers. It also brings potential benefits to learners in less developed countries where proprietary software or resources are effectively inaccessible. Lastly, the procedure of using a Creative Commons licence to reuse, share, and develop derivative resources is rewarded by the requirement to share the new OER in appropriate digital repositories, thus benefiting everyone with the improvements and/or contextual changes.

From the perspective of the student, there are two reported advantages to the use of OER materials in course construction. The primary advantage is to enable easy access by learners to alternative ways of learning about a subject/topic than is covered in the course of their studiesto revise, to delve more deeply, or simply to have the same material explained in a different manner by another scholar. Although the initial advantage is mainly direct access to high-quality OER that tutors have drawn to their students' attention, many students are quick to identify such repositories (e.g., Academic Earth, iTunes, Creative Commons, Flickr) as valuable resources that they can explore for themselves. This is encouraged by the seal of approval given to trusted sources indicated by their tutor. A secondary advantage for learners is the speed of course construction facilitated by OER use as this enables tutors to augment the resources on the course as they are discovered on more or less a real-time basis. Unlike conventional courses that are based on textbooks and lectures, the addition of digital educational resources can be added to the web links of a course if, for example an article or video becomes open for circulation, even after it has been covered in the course schedule; students like the freshness and topicality of this facility.

\section{Lessons Learned}

1) Have a clear idea what subjects/concepts you want the course to cover in general, but remain flexible over the specific teaching content. 
2) Some sources of OER are more useful and reliable than others and usually come from trusted "brands" (such as esteemed universities), although many of the smaller OER that are generated by less well-known individuals can be of equally high quality. (We suspect that this issue of "big OER" versus "small OER" will become a highly contested area for education in the near future.)

3) Be flexible and patient in your initial searches for OER sources and courses - different keywords will generate different searches, and it may take time and ingenuity to locate and recognise exactly what you are looking for.

4) The process itself helps to clarify the educational objectives and the desired outcomes of the course to be constructed. Openness to the availability and reuse of OER encourages pedagogical innovation in the incorporation of educational technology.

5) It is best to save the completed course in a variety of formats to enable the widest possible access for learners.

6) The creation of new OER to fill perceived gaps, which can then be added to the global OER pool, may initially be intimidating, but this is quickly superseded by the realisation that the benefits outweigh the time invested.

\section{Conclusions}

The practical experimentation in the project led to the conclusion that while it is relatively easy to find open access resources for educational reuse, it is much more difficult to locate precise OER for specific purposes within even a loosely pre-arranged course structure. There are several immediate reasons for this: firstly, the difficulties in locating relevant resources easily, due to inadequate Internet search skills and or poor tagging of resources (although both of these should improve with use); secondly, many OER are too large (e.g., video clips longer than 15 minutes) to drop into a course structure without skewing the proposed course structure in a manner that was not intended; thirdly (and partly in relation to the second point), some OER cover a wider range of topics than is being sought, and course constructors may be reluctant to edit these OER, even if this is permissible; fourthly, access to some digital resources may require taking steps that are unavailable or unfamiliar to the person searching and therefore discourage exploration; fifthly, some specifically sought resources (e.g., particular academic journals) are not yet available as open resources (although this too may change with time).

From the perspective of the educator attempting to pull together a new course, there is clearly a balancing point where the skills and time needed to locate relevant OER that can be reused in a course is counterbalanced by the skills and time required to generate new educational resources from scratch. The responses to this may largely be governed by the subject matter and level of the course, for example, good quality photographs for an introductory geography course may be readily available on Creative Commons Flickr, whereas comparable quality images for specific medical or engineering subject matter may not. Partly, too, the use of OER may be determined by 
their educational function within the new course, that is are they intended to cover need-to-know areas of the curriculum, or are they intended to cover nice-to-know areas, where students might be encouraged to watch/listen to the views of other scholars (even contrary views to provoke discussion)? With the former, the size and exact relevance of the OER is a crucial issue, requiring short, specific resources, for example, a good diagram, a succinct explanation of a conceptual point, or an illustration with an appropriate example. With reference to the nice-to-know additional educational resources, these may be deployed simply to provide extra layers of perspective for learners seeking a deeper subject understanding.

We found the institutional attitudes to the wider adoption of OER constraining in two areas. On the one hand, there is often a reluctance to reuse resources that appear to be too heavily branded by another institution, perhaps indicating an apprehension that this may be seen as an admission of being in the shadow, or otherwise inferior, to the branded institution. On the other hand, there is also an uncertainty among many academic staff as to whether they as individuals, their institutional employers, or the world at large should be the owners of the intellectual property that they create. To some extent this confusion is being addressed by open access educational initiatives such as OpenLearn (2010) and OpenCourseWare (2010), but these are relatively small cutting-edge initiatives within a large sea of higher education curriculum materials. Apart from a few instances where institutions have taken a strategic lead (and even here), the OER "movement” has largely progressed by the work of individual early adopters.

From the perspective of the learner, the incorporation of OER into course delivery may be relatively discrete (as in images included within an explanatory text) or blatantly obvious (as in the situation where students are referred to external, branded sites such as YouTube, iTunes, and Academic Earth). In neither case did our pilot group of users voice any objections to using OER; rather, the main concern was whether the sites were considered to be reliable educational resources, and in this they were largely reassured due to the fact that their "lecturers" (i.e., the course designers) were seen to be recommending these resources to the students and pre-selecting the OER to be included in the course. The two minor areas of concern that were raised related to the need for students to register with external service providers and to the technical confidence of the students to download and install any necessary software. As with other aspects of online education, dealing with these issues at a comprehensive student induction at the start of the course may dispel these initial concerns.

In conclusion, the experiment to locate and reuse OER in the construction of complete higher education courses was a qualified success. Two areas of proposed further investigation are the skill sets required by academics to locate, identify, and recombine OER into their course materials and the experience of learners in using these hybrid course resources (OER plus contextual original materials) for their own study (especially to what extent they are tempted to continue to explore identified trustworthy sources for their own self-motivated study activities). 


\section{Using OER in Course Design}
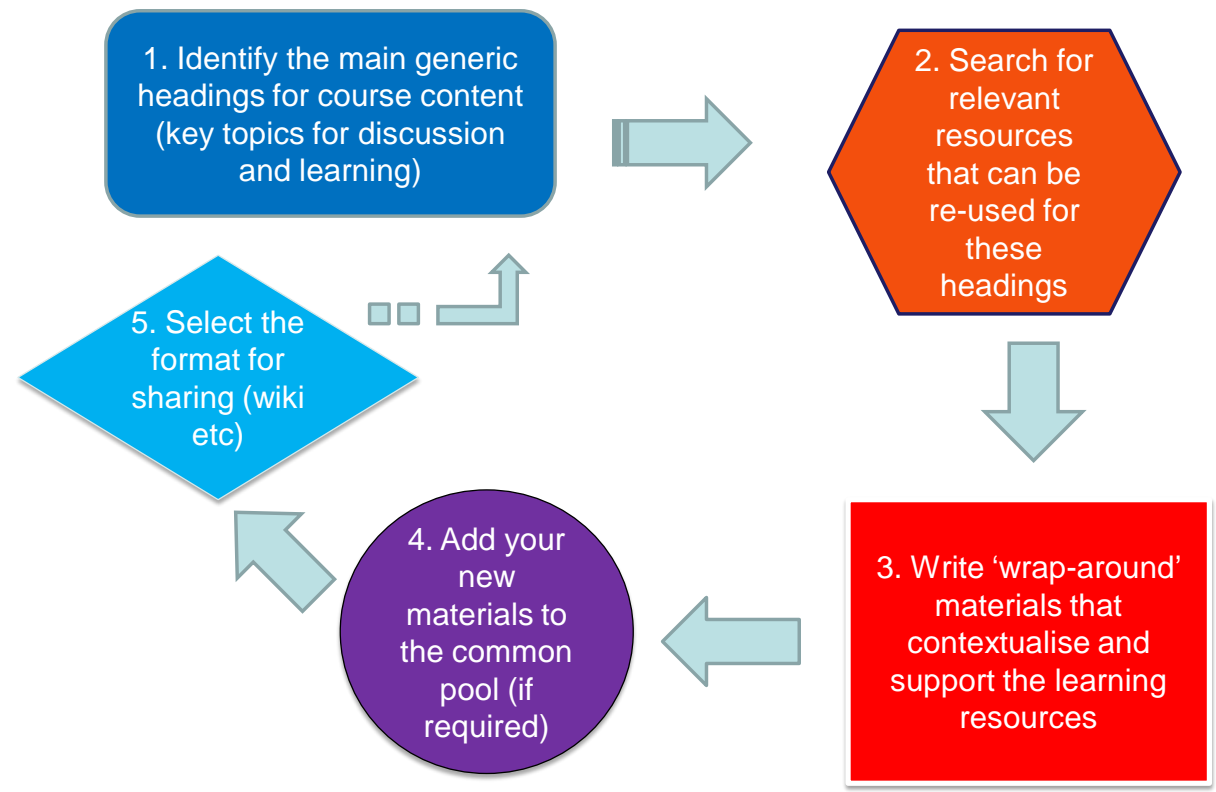

Figure 3. Summary of course design process using OER. 


\section{References}

Commonwealth of Learning (2005). Creating learning materials for open and distance learning: A handbook for authors and instructional designers. Retrieved from http://www.col.org/SiteCollectionDocuments/odlinstdesignHB2.pdf

Davis, A. (2004). Developing an infrastructure for online learning. In T. Anderson \& F. Elloumi, (Eds.), Theory and practice of online learning (Chapter 4). Athabasca, AB: Athabasca University Press. Retrieved from http://cde.athabascau.ca/online_book/

Downes, S. (2006). Models for sustainable open educational resources. National Research Council of Canada. Retrieved from www.oecd.org/document/32/0,2340,en_2649_33723_36224352_1_1_1_1,00.html

Gurell S., \& Wiley, D. (2010). Open educational resources handbook 1.0 for educators. Retrieved from http://wikieducator.org/OER_Handbook/educator_version_one

Guthrie, K., Griffiths, R., \& Maron, N. (2008). Sustainability and revenue models for online academic resources. Retrieved from http://www.jisc.ac.uk/publications/programmerelated/2008/scaithakasustainability.aspx

Haughey, M., \& Anderson, T. (1998). Networked learning: The pedagogy of the Internet. Toronto, ON: Cheneliere/McGraw-Hill.

Hills, G., \& Lingard, R. (2003). UHI: The making of a university. Ediburgh: Dunedin Academic Press.

Jóhannesdóttir, S. (2007). Samstarfsnet háskóla og símenntunarmiðstöðva Demó. Report to the Ministry of Education, Science and Culture in Iceland. Reykjavík.

Jóhannesdóttir, S. (2008). Netháskólinn, skýrsla byggð á viðtölum við samstarfsháskóla. Report to the Ministry of Education, Science and Culture in Iceland. Reykjavík.

Mason, R., \& Rennie, F. (2008). Social implications of three different models of distributed learning. In T. Kidd \& I. Chen (Eds.), Social information technology: Connecting society and cultural issues (Chapter 21). IGI Global.

Ministry of Education, Science and Culture. (2005). Ministry of education, science and culture in Iceland. Publication No. 18. Reykjavík: Ministry of Education, Science and Culture.

OECD. (2007). Giving knowledge for free: The emergence of open educational resources. Retrieved from www.sourceoecd.org/education/9789264031746 
OpenCourseWare. (2010). The landing page of the MIT Open Courseware initiative. Retrieved from http://ocw.mit.edu/OcwWeb/web/home/home/index.htm

OpenLearn. (2010). The learning space of the UK open university open courseware initiative. Retrieved from http://openlearn.open.ac.uk

Rennie, F. (2008). Flexible delivery in action: the case of the University of the Highlands and Islands. In M. Weaver (Ed.), Transformative learning support models in higher education: Educating the whole student (Chapter 7). London: Facet Publishing.

Rennie, F., \& Weller, M. (Eds.). (2010). Open to all: Designing digital courses using open educational resources. Blurb Publishing. Retrieved from http://www.blurb.com/bookstore/detail/1267854

SideCAP. (2010). Project documentation of the "Staff Innovation in Distributed Education in the Caribbean, African, and Pacific countries” project. See especially the resources pages. Retrieved from www.sidecap.wetpaint.com

Statistics Iceland. (2009). Retrieved from http://www.hagstofa.is

Thórsteinsdóttir, G. R. (2006). Fjarnám erlendis: Skipulag fjarnáms á háskólastigi í Frakklandi, Kanada, Skotlandi og Svípjóð. Skýrsla unnin fyrir Menntamálaráðuneytið. RHA. (38 $\quad$ s.) Retrieved from http://www.rha.is/?mod=sidur\&mod2=view\&id=18

Thórsteinsdóttir, G. R., et al. (2007). Fjarnám við íslenska háskóla: úttekt og stöðugreining. Reykjavík: Ministry of Education, Science and Culture. Retrieved from http://www.rha.is/skrar/File/Rannsoknir/2007/fjarnam_isl_hask_lokask.pdf

Thórsteinsdóttir, G. R., Kristinsdóttir, S., Jóelsdóttir, S. S., Rennie, F., \& Hultman, S., \& Downes, S. (2009). Transfer of innovation in continuing university education: The best practice report. $\quad$ Retrieved from http://www.leonardodavinciprojekte.org/adam/project/view.htm?prj=5095

Weller, M. (2010a). Let's play OER roulette. Retrieved from http://nogoodreason.typepad.co.uk/no_good_reason/2010/11/lets-play-oer-roulette.html

Weller, M. (2010b). Every day I write the book. Retrieved from http://nogoodreason.typepad.co.uk/no good reason/2010/09/everyday-i-write-thebook.html

Wiley, D. (2007). On the sustainability of open educational resource initiatives in higher education. Retrieved from the OECD Centre for Educational Research and Innovation/CERI: http://www.oecd.org/edu/oer 


\section{Athabasca University $\mathbf{A}$}

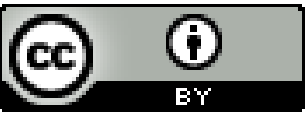

